Chronic Obstructive Pulmonary Diseases: Journal of the COPD Foundation

Original Research

\title{
Significance of Patent Foramen Ovale in Patients with GOLD Stage II Chronic Obstructive Pulmonary Disease (COPD)
}

Dario Martolini, MD, ${ }^{1,2}$ Rebecca Tanner, BSc, ${ }^{1}$ Claire Davey, MSc, ${ }^{1}$ Mehul S. Patel, MS, MBBS, BSc, MRCP, ${ }^{1}$ Davide Elia, MD, ${ }^{1}$ Helen Purcell, BSc, ${ }^{1}$ Paolo Palange, MD, ${ }^{2}$ Nicholas S. Hopkinson, PhD, FRCP, ${ }^{1}$ and Michael I. Polkey, PhD, FRCP ${ }^{1}$

\section{Abstract}

Background: Patent foramen ovale (PFO) is a common finding in adults. A PFO is associated with right to left shunting but its importance in the aetiology of hypoxia in early COPD remains uncertain, although it has not proved possible to demonstrate a role for PFOs in the aetiology of hypoxia in patients with Global Initiative for chronic Obstructive Lung Disease (GOLD) stage III/IV disease. We compared the characteristics of GOLD stage II patients with or without a PFO and assessed its impact on exercise performance.

Methods: In 22 GOLD stage II COPD patients we measured exercise performance, arterial oxygen tension and lung function and used contrast transcranial Doppler ultrasonography (TCD) to assess the presence of a PFO. Patients $(n=20)$ underwent TCD measurements during incremental cycle ergometry with respiratory pressures measured using an esophageal balloon catheter $(n=13)$.

Results: Twelve individuals (54\%) had a PFO. Patients with a PFO were more hypoxic; mean(SD) partial pressure of oxygen in arterial blood $\left(\mathrm{PaO}_{2}\right)$ 10.2(1.1) kilopascals $(\mathrm{kPa})$ vs. 11.7(0.9)kPa $(\mathrm{p}<0.01)$, but the presence of a PFO was not associated with reduced exercise performance either on cycle ergometry or a 6 Minute Walk Test (6MWT). A strong relationship was noted between the esophageal pressure swing $\left(\mathrm{P}_{\text {SwingEs }}\right)$ and the degree of shunting observed during exercise $(\mathrm{r}=0.7 ; \mathrm{p}<0.001)$.

Conclusions: The presence of a PFO in GOLD stage II COPD patients does not appear to influence exercise performance despite increased right-to-left shunting.

\footnotetext{
Abbreviations: patent foramen ovale, PFO; Global Initiative for chronic Obstructive Pulmonary Disease, GOLD; transcranial Doppler ultrasonography, TCD; transesophageal echocardiography, TEE; partial pressure of oxygen in arterial blood, $\mathrm{PaO}_{2}$; 6 minute walk test,

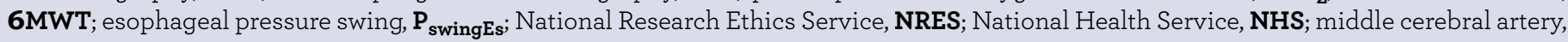
MCA; high intensity transient signals, HITS; oxygen uptake, $\mathbf{V}^{\prime} \mathbf{O}_{\mathbf{2}}$; carbon dioxide output, $\mathbf{V}^{\prime} \mathbf{C O}_{2}$; ventilation, V' $\mathbf{E}$; heart rate, HR; respiratory rate, $\mathbf{R R}$; arterial oxygen saturation, $\mathrm{SpO}_{2}$; cardiopulmonary exercise testing, $\mathbf{C P E T}$; carbon monoxide diffusing capacity, $\mathbf{T L}_{\mathbf{C O}}$; arterial blood gases analysis, ABG; European Respiratory Society, ERS; American Thoracic Society, ATS; St. George's Respiratory Questionaire, SGRQ; Medical Research Council, MRC; Headache Impact Test, HIT-6; Analysis of Variance, ANOVA; patients with a PFO, PFO+; patients without a PFO, PFO-; body mass index, BMI;

Funding Support: This research is supported by the National Institute of Health Research Respiratory Biomedical Research Unit at the Royal Brompton and Harefield National Health Service Foundation Trust and Imperial College, London, who partially fund Michael Polkey's salary.

Date of Acceptance: June 13, 2014

Citation: Martolini D, Tanner R, Davey C, et al. Significance of patent foramen ovale in patients with GOLD Stage II chronic obstructive pulmonary disease (COPD). J COPD F. 2014; 185-192. doi: http://dx.doi.org/10.15326/jcopdf.1.2.2013.0003
}

\section{This article has an online data supplement.}

1 National Institute for Health Research (NIHR) Respiratory Biomedical Research Unit, Royal Brompton \& Harefield National Health Service (NHS) Foundation Trust and Imperial College, London, United Kingdom
2 Laboratory of Respiratory Pathophysiology, Department of Public Health and Infectious Diseases, Sapienza University of Rome, Italy 


\section{Address correspondence to:}

Michael I. Polkey, PhD, FRCP

NIHR Respiratory Biomedical Research Unit,

Royal Brompton \& Harefield

NHS Foundation Trust and Imperial College, London, UK m.polkey@imperial.ac.uk

\section{Keywords:}

chronic obstructive pulmonary disease; exercise and lung function; arterial oxygenation

\section{Background}

A patent foramen ovale ( $\mathrm{PFO}$ ) is present when the normal fetal communication between the right and left atria persists or recurs after birth. ${ }^{1}$ Presence of a $\mathrm{PFO}$ is a common finding, occurring in up to $34 \%$ of the population and, although the prevalence decreases with age, those identified at post mortem in older people tend to be larger. ${ }^{2}$ In most cases, a PFO poses no threat to health but, under certain hemodynamic conditions, when there is a pressure gradient from the right to left atria, a PFO can allow deoxygenated blood to shunt from the venous to the arterial circulation.

We have previously reported an increased prevalence of large PFOs in patients with Global Initiative for chronic Obstructive Lung Disease (GOLD) stage III/IV $\mathrm{COPD}^{3}$, and prior smaller studies ${ }^{4,5}$ had even suggested that a PFO contributes to hypoxemia, increased dyspnea and reduced exercise tolerance although this was not the conclusion of our own study. One explanation for these findings could be that the primary limitation to exercise in patients with GOLD stage III/IV disease is pulmonary and thus a PFO could cause greater exercise limitation in patients with spirometrically milder disease; however no data at all exist in patients with milder disease except those of Kilic et al who specifically sought patients who also had disproportionate hypoxia. ${ }^{6}$

Since the current data do not permit definitive conclusions to be drawn regarding patients with milder disease who nonetheless are affected in terms of breathlessness, reduced exercise performance and physical activity, ${ }^{7,8}$ we studied patients with GOLD stage II COPD to determine whether the presence of a $\mathrm{PFO}$ influences the arterial oxygen level at rest, whether the right to left shunt increases during exercise in those with a PFO and whether the presence of a PFO is associated with reduced exercise tolerance.

\section{Materials and Methods:}

\section{Patients and Study Design}

This study was approved by the National Research Ethics Service (NRES) Committee (London) and by the Ethics Committee of Royal Brompton and Harefield National Health Service (NHS) Foundation Trust, reference number 11/LO/0402. All participants provided written informed consent. Every GOLD stage II COPD patient who attended our research lab or our outpatient clinic was invited to take part in our study. A convenience sample of 22 patients ( 13 male $/ 9$ female) available at the same time as the investigators, with a mean age of $66 \pm 9$ years (range 44 to 81 ) were studied. The diagnosis of COPD was made according to the GOLD guidelines. ${ }^{9}$ Patients with other respiratory or cardiac diseases were excluded from the study.

\section{Patent Foramen Ovale Detection}

Contrast-enhanced transcranial Doppler ultrasonography (TCD) was used to diagnose the presence of a PFO. In our previous study ${ }^{3}$ and others, TCD showed a good accuracy compared to the gold standard contrast transesophageal echocardiography (TEE). ${ }^{10,}{ }^{11}$ A $2 \mathrm{MHz}$ Power M-Mode digital TCD system (ST3/ PMD150, Spencer Technologies, Seattle, WA) was used. With the individual in the supine position, the middle cerebral artery (MCA) was insonated bilaterally through temporal bone windows at a depth of 35 to 60 $\mathrm{mm}$ and the probes were held in place by a headset. Agitated saline was prepared with $9 \mathrm{~mL}$ of saline and $1 \mathrm{~mL}$ of air. Microbubble injections, via an intravenous cannula inserted in the right antecubital vein, were performed twice at rest, and twice 5 seconds before a Valsalva maneuver lasting 10 seconds. ${ }^{12}$ High-intensity transient signals (HITS) were counted for 25 seconds after the injection. To confirm PFO presence, at least 1 HITS had to be spotted. Grading was scored using the criteria of Spencer ${ }^{11}$ based on a visual scale and on the number of bubbles (HITS) identified and ranges of from 1 to 10 HITS (Grade I) to 11 to 300 (Grade II-IV) to more than 300 HITS or the so called curtain effect (Grade V-V+).

\section{Cardiopulmonary Exercise Test}

Patients were asked to sit on an electromagnetically braked cycle ergometer (Ergoline, Germany) while connected by a mouthpiece to a breath-by-breath gas analyzer (Jaeger, Germany). Oxygen uptake $\left(\mathrm{V}^{\prime} \mathrm{O}_{2}\right)$, 
carbon dioxide output $\left(\mathrm{V}^{\prime} \mathrm{CO}_{2}\right)$, ventilation ( $\mathrm{V}_{\mathrm{E}}^{\prime}$ ), respiratory rate $(\mathrm{RR})$, heart rate $(\mathrm{HR})$ and other derived variables (i.e. ventilatory equivalent of $\mathrm{C}^{\prime} \mathrm{O}_{2}, \mathrm{~V}_{\mathrm{E}} / \mathrm{V}^{\prime} \mathrm{CO}_{2}$ ) were measured. A finger pulse oximeter was placed for monitoring arterial oxygen saturation $\left(\mathrm{SpO}_{2}\right)$. After 2 minutes of rest and 1 minute of warm-up at 10 watts, increments of 10 or 15 watts were implemented every minute. The increment was adjusted to provide an estimated loaded period of at least 8 minutes. Patients were asked to cycle at 60 revolutions per minute until exhaustion. During the rest phase and immediately before the termination of exercise, an arterialized blood sample was taken from the earlobe for gas analysis. ${ }^{13}$ To evaluate the degree of shunting during the test, TCD monitoring was maintained and agitated saline was injected every 2 minutes.

\section{Measurement of Intrathoracic and Gastric Pressures}

Before cardiopulmonary exercise testing (CPET), a balloon catheter to measure the intrathoracic (esophageal) pressure was advanced through the nose and positioned into the esophagus. The esophageal balloon was inflated with $0.5 \mathrm{ml}$ of air. The catheter was connected to differential pressure transducers (Validyne MP45, USA) and the signal, amplified and converted from analogue to digital and transferred to a computer running Labview ${ }^{\mathrm{TM}}$ Software (National Instruments, USA). During the entire exercise test the signal was monitored and saved for subsequent analysis.

\section{Lung Function and 6 Minute Walking Test}

Spirometry, plethysmographic lung volumes, carbon monoxide diffusing capacity (TLco) (Compact Lab system; Jaeger, Wurzburg, Germany), arterial blood gas analysis (ABG) of breathing room air and the 6 minute walking test (6MWT) were determined in accordance with European Respiratory Society (ERS) /American Thoracic Society (ATS) recommendations. ${ }^{14-17}$

\section{Questionnaires}

Health-related quality of life was determined using the St. George's Respiratory Questionnaire (SGRQ) and breathlessness assessed according to the Medical Research Council (MRC) dyspnea score. The Headache Impact Test (HIT-6) was used to evaluate headache symptoms and the Epworth Sleepiness scale to assess daytime somnolence since we have previously shown that large PFOs are more common in patients with obstructive sleep apnea. $^{18}$

\section{Statistical Analysis}

For comparison of variables between groups (with and without PFOs) the Mann-Whitney U test was used since the sample size made it likely that the data would not be normally distributed. An independent effect of the presence of a PFO on exercise capacity was evaluated using stepwise regression analysis incorporating other factors that might influence exercise including spirometry, gas diffusion capacity, blood gas parameters and anthropometrics. Analysis of Variance (ANOVA) was used to evaluate the difference in terms of number of HITS observed after the saline injections among the different phases of the exercise. Spearman rank correlation was used to assess the correlation between the $\mathrm{P}_{\text {SwingEs }}$ and the number of HITS observed. A $p$ value $<0.05$ was considered significant.

\section{Results}

\section{Baseline}

Twenty-two individuals participated in the study (see online supplement, Consort Diagram, Figure 1). All patients completed the cross-sectional evaluation at rest and so underwent $A B G$, lung function, $6 \mathrm{MWT}$, questionnaires and TCD. We detected a PFO in 12 of the 22 patients evaluated (54\% prevalence). Of those with a PFO, 8 (66\%) had a Grade I PFO, 1 (8\%) a Grade II, 2 (16\%) a Grade III and 1 patient (8\%) a Grade IV. Patients with a PFO $\left(\mathrm{PFO}^{+}\right)$were significantly older than those without $\left(\mathrm{PFO}^{-}\right)(p<0.05)$, with a lower TLco percent predicted $(p<0.002)$ (Table 1$)$, lower FEV1/FVC ratio $(p<0.02)$ and were more hypoxic $(p<0.01)$. In univariate analysis PFO presence, FEV1 \%predicted, FEV1/FVC ratio, and TLco \%predicted, but not age, correlated with $\mathrm{PaO}_{2}(\mathrm{r}=0.61,0.44,0.54,0.52, p<0.05)$. In stepwise regression only the presence of a $\mathrm{PFO}$ was retained as an independent correlate of $\mathrm{PaO}_{2}$ explaining $37 \%$ of the variation. There was no difference in breathlessness or health status between patients with or without a PFO (Table 2), although those with a PFO had a higher BODE index (Table 1). 
Table 1. Comparison of Lung Function, Blood Gas Analysis and 6MWT Distance

\begin{tabular}{|c|c|c|c|}
\hline & $\begin{array}{c}\mathrm{PFO}^{-} \\
\text {Mean } \pm \text { SD }\end{array}$ & $\begin{array}{c}\mathrm{PFO}^{+} \\
\text {Mean } \pm \text { SD }\end{array}$ & $p$ Value $^{2}$ \\
\hline $\mathrm{N}$ & 10 & 12 & - \\
\hline Sex, $M / F$ & $7 / 3$ & $6 / 6$ & NS \\
\hline Age, years & $62.3 \pm 10$ & $69.5 \pm 6$ & 0.046 \\
\hline Smoking History, pack/years & $28.6 \pm 20$ & $39.2 \pm 14$ & 0.075 \\
\hline BMI, $\mathrm{kg} / \mathrm{m}^{2}$ & $29.3 \pm 4.3$ & $26.3 \pm 4.8$ & 0.11 \\
\hline $\mathrm{FEV}_{\mathbf{1}}, \mathrm{L}$ & $2.05 \pm 0.40$ & $1.55 \pm 0.33$ & 0.016 \\
\hline FEV $_{1} \%$ pred & $68.7 \pm 9.9$ & $61.4 \pm 9.4$ & 0.086 \\
\hline FVC, L & $3.65 \pm 0.9$ & $3.40 \pm 0.9$ & NS \\
\hline FVC \%pred & $96.5 \pm 12$ & $106.3 \pm 13$ & 0.086 \\
\hline $\mathrm{FEV}_{1} / \mathrm{FVC}$ & $0.54 \pm 0.09$ & $0.44 \pm 0.07$ & 0.018 \\
\hline TLC \%pred & $103 \pm 21$ & $115 \pm 11$ & 0.051 \\
\hline RV/TLC \%pred & $109 \pm 18$ & $117 \pm 14$ & NS \\
\hline TLco, \%pred & $79 \pm 7$ & $62 \pm 13$ & 0.0019 \\
\hline $\mathrm{PaO}_{2}, \mathrm{kPa}$ & $11.6 \pm 0.8$ & $10.1 \pm 1.1$ & 0.0051 \\
\hline $\mathrm{PaCO}_{2}, \mathrm{kPa}$ & $4.5 \pm 0.5$ & $4.6 \pm 0.4$ & NS \\
\hline $\mathrm{SpO}_{2}, \%$ & $97 \pm 0.64$ & $96 \pm 0.8$ & 0.0008 \\
\hline 6MWT, meters & $492 \pm 46$ & $485 \pm 121$ & NS \\
\hline BODE & $0.40 \pm 0.51$ & $1.25 \pm 0.96$ & 0.039 \\
\hline
\end{tabular}

Table 2. Health Status and Symptoms in COPD Patients With or Without a PFO

\begin{tabular}{l|c|c|c} 
& $\begin{array}{c}\mathrm{PFO}^{-}(\mathbf{n}=\mathbf{8}) \\
\text { Mean } \pm \text { SD }\end{array}$ & $\begin{array}{c}\mathbf{P F O}^{+}(\mathbf{n}=\mathbf{1 2}) \\
\text { Mean } \pm \mathbf{S D}\end{array}$ & $p$ Value \\
\hline MRC & $1.7 \pm 0.67$ & $1.92 \pm 0.9$ & NS \\
\hline SGRQ Score & $39 \pm 23$ & $34 \pm 12$ & NS \\
\hline Activity Score & $44 \pm 18$ & $48 \pm 24$ & NS \\
\hline Impact Score & $18 \pm 13$ & $19 \pm 10$ & NS \\
\hline Total Score & $29 \pm 14$ & $30 \pm 13$ & NS \\
\hline HIT-6 & $41 \pm 5$ & $42 \pm 6$ & NS \\
\hline Epworth Sleepiness Scale & $5.8 \pm 4.9$ & $5.6 \pm 4.2$ & NS \\
\hline${ }^{2}$ Mann-Whitney U Test & &
\end{tabular}

Table 3. Comparison Between the Two Groups in Terms of CPET.

\begin{tabular}{|c|c|c|c|}
\hline & $\begin{array}{l}\mathrm{PFO}^{-}(n=8) \\
\text { Mean } \pm \text { SD }\end{array}$ & $\begin{array}{c}\mathrm{PFO}^{+}(n=12) \\
\text { Mean } \pm \mathrm{SD}\end{array}$ & $p$ Value $^{\mathrm{b}}$ \\
\hline $\mathrm{V}^{\prime} \mathrm{O}_{2}$ Peak, $\mathrm{ml} / \mathrm{min}$ & $1787 \pm 500$ & $1353 \pm 277$ & 0.049 \\
\hline $\mathrm{V}^{\prime} \mathrm{O}_{2}$ Peak $/ \mathrm{Kg}, \mathrm{ml} / \mathrm{min} / \mathrm{Kg}$ & $21.2 \pm 4.2$ & $18.46 \pm 4.8$ & NS \\
\hline $\mathrm{V}^{\prime} \mathrm{O}_{2}$ Peak \%pred & $92 \pm 19$ & $89 \pm 19$ & NS \\
\hline $\mathrm{V}^{\prime} \mathrm{O}_{2} @ \mathrm{AT}$ \%pred & $60 \pm 12$ & $59 \pm 14$ & NS \\
\hline V'E Peak, L/min & $65 \pm 12$ & $54 \pm 11$ & 0.076 \\
\hline V'E Peak/MVV \% & $80 \pm 19$ & $87 \pm 10$ & NS \\
\hline V'E/V'CO ${ }_{2} @ A T$ & $30 \pm 4.2$ & $35 \pm 4$ & 0.037 \\
\hline V'E/V'CO ${ }_{2} @$ Peak & $34 \pm 3$ & $37 \pm 5$ & NS \\
\hline HR Peak, bpm & $137 \pm 15$ & $134 \pm 21$ & NS \\
\hline HR Peak, \%pred & $86 \pm 9$ & $89 \pm 12$ & NS \\
\hline $\mathrm{SpO}_{2}$ Rest, $\%$ & $98 \pm 1$ & $96 \pm 2$ & 0.049 \\
\hline $\mathrm{SpO}_{2}$ Peak, $\%$ & $96 \pm 2$ & $94 \pm 4$ & 0.17 \\
\hline $\mathrm{PaO}_{2}$ Rest, $\mathrm{kPa}$ & $11.7 \pm 0.9$ & $10.1 \pm 1.1$ & 0.0097 \\
\hline $\mathrm{PaO}_{2}$ End Exercise, $\mathrm{kPa}^{\mathrm{a}}$ & $11.9 \pm 1.4$ & $11 \pm 1.6$ & NS \\
\hline Load, \%pred & $84 \pm 34$ & $97 \pm 36$ & NS \\
\hline
\end{tabular}

\section{Exercise}

Of the 22 patients recruited, 2 individuals $\left(\mathrm{PFO}^{-}\right)$did not undergo the CPET. One declined to perform it and the other was excluded because the subsequent identification of ischemic heart disease made them unsuitable for performing the CPET. Nonetheless, the demographics and lung function profile between the 2 groups without these 2 patients were unchanged.

$\mathrm{V}^{\prime} \mathrm{O}_{2}$ peak adjusted for body weight did not differ significantly between groups (Table 3 ) and in univariate analysis it correlated significantly with body mass index (BMI) (r -0.53) and TLco \%predicted ( $r \quad 0.55)$ but not with age, $\mathrm{FEV}_{1}$ or with $\mathrm{PaO}_{2}$ at rest or the presence of a PFO. In a stepwise regression model only BMI and TLco\%predicted were retained explaining $74 \%$ of the variance in $\mathrm{VO}_{2}$ peak $/ \mathrm{kg}$. Performing a similar analysis for the 6 minute walk distance, the presence of a PFO again did not influence exercise performance and this again was associated with TLco and BMI giving an $\mathrm{r}^{2}$ of 0.33 .

Of the 20 individuals who exercised, $8 \mathrm{PFO}^{+}$and $5 \mathrm{PFO}^{-}$ individuals performed a technically reliable exercise test with good data acquisition, either from the point of view of the TCD signal, with successful administration of the agitated saline injections, and from the point of view of the esophageal pressure recording during exercise. As shown in Figure 1 there was a tendency for a shunt increase (number of HITS observed) with exercise, although there was no significant difference between the different phases of the exercise. However,

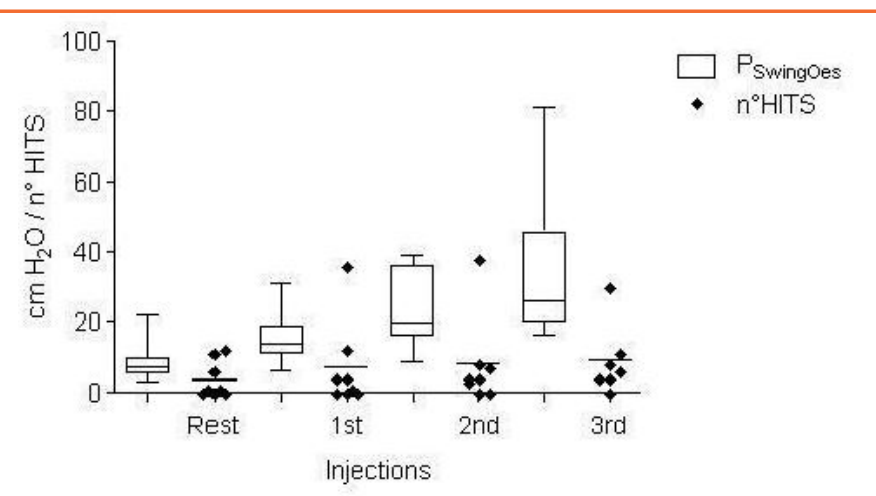

Figure 1. Comparison between $\mathrm{P}_{\text {SwingEs }}$ and HITS in $\mathrm{PFO}^{+}$patients; note that technically acceptable injections were not obtained at each time point in all individuals.

as shown in Figure 2 there was a strong correlation between the $\mathrm{P}_{\text {SwingEs }}$ and the number of HITS observed at every injection ( $\mathrm{r}=0.701$, $\mathrm{p}<0.001)$. Injections which were not followed by HITS appearance were excluded in this analysis. 


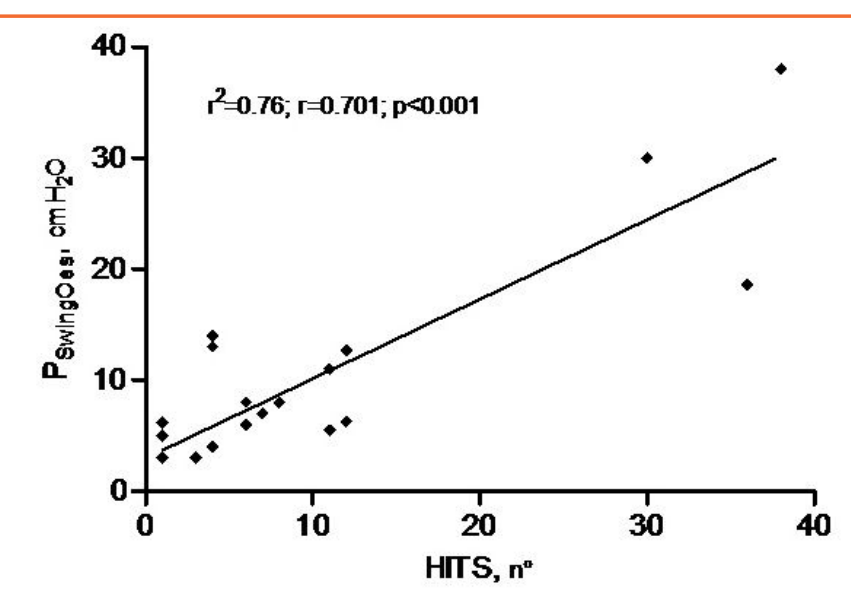

Figure 2. Correlation (Spearman) between HITS and $P_{\text {SwingEs }}$ in $\mathrm{PFO}^{+}$patients $(\mathrm{n}=8)$

As expected, HITS were almost completely absent in the $\mathrm{PFO}^{-}$group (see Figure 3 ). In the case of $\mathrm{PFO}^{+}$patients the absence of HITS during the exercise test rest phase may have been due to the seated position assumed compared to the supine position of the PFO detection test.

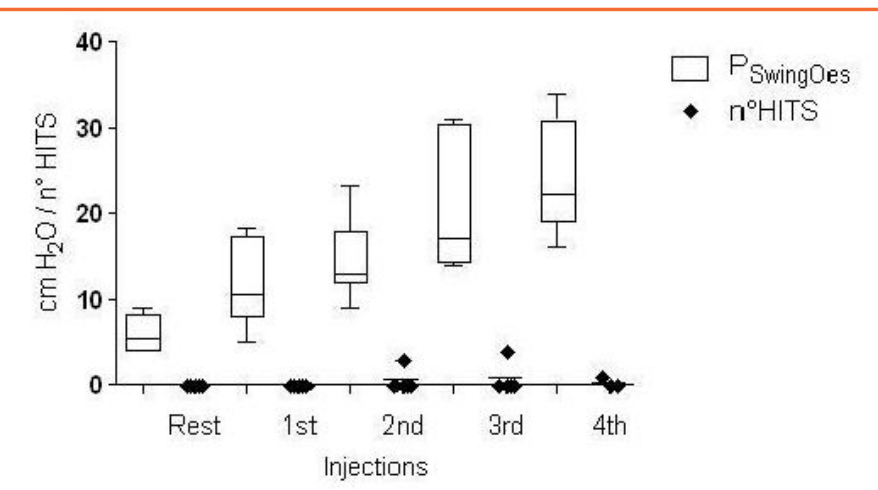

Figure 3. Comparison between $\mathrm{P}_{\text {SwingEs }}$ and HITS in $\mathrm{PFO}^{-}$patients $(n=5)$; note that technically acceptable injections were not obtained at each time point in all individuals.

Moreover, no Valsalva maneuver was requested during the cycling test. The reduced venous return while in the sitting position and during resting breathing could also explain the absence of HITS in some $\mathrm{PFO}^{+}$patients at the beginning of the exercise as shown in Figure 1.

\section{Discussion}

The main finding of the present study is that although PFOs are reasonably common in GOLD stage II patients and associated with a modest reduction in resting $\mathrm{PaO}_{2}$, the presence of a $\mathrm{PFO}$ was not associated with reduced exercise capacity either during incremental cycle ergmometry or during the 6MWT. During exercise, there was a strong relationship between increased respiratory muscle work (judged by esophageal pressure) and an increase in right to left shunting. Overall, our data do not support a role for PFOs in the aetiology of exercise limitation in COPD patients with GOLD stage II disease.

\section{Methodological Issues}

It has previously been noted that the use of high flow oxygen can mask the presence of a PFO, ${ }^{19}$ most probably by the mechanism that oxygen induced vasodilation acts to reduce shunt volume. For this reason, in the present study all TCD studies were performed with the patient breathing room air.

Our approach differed from Kilic et al who selected patients with disproportionate hypoxia. ${ }^{6}$ Our participants were a convenience sample of GOLD stage II COPD patients passing through our clinical service who were invited to take part in the study irrespective of the oxygen level. We are unable to make any definitive comment about the incidence of PFOs in our study group since to do so would require a larger cohort of patients and an age matched, control group. Nevertheless, the overall prevalence (12 of 22 altogether and 3 of 22 with large PFOs) is within the range expected from autopsy studies $^{2}$ and from studies including patients with more severe disease. ${ }^{3-5}$ However, our results are in contrast with the only study that so far evaluated mild COPD and which found a prevalence of PFOs around 20 percent. $^{6}$

Transcranial Doppler ultrasonography was used as a diagnostic mode in this study because we doubted our ability to obtain satisfactory 4-chamber views by transthoracic echocardiography during exercise particularly in patients with COPD in which echo windows are poor because of gas trapping and hyperinflation. The gold standard of transesophageal echocardiography would of course also have been impractical during exercise studies. Previous studies suggest a reasonable concordance between transthoracic echocardiography and transcranial Doppler, ${ }^{20,21}$ and this was our experience in GOLD stage III/IV COPD patients. ${ }^{3}$

\section{Significance of the Findings}

In this study we sought to determine if the presence of PFOs in patients with GOLD stage II COPD was associated with a phenotypic disadvantage, and particularly, if patients with a PFO were more hypoxic. A second aim was to assess the effect of exercise on right to left shunting. 
The PFO group were almost $1 \mathrm{kPa}$ more hypoxic than those without a PFO. Such a result is in agreement with our starting hypothesis that PFOs are associated with right to left shunting which causes relative (compared to those without a PFO) hypoxia. However, this observation should not be accepted uncritically since over half of the PFOs identified (66\%) were small Grade I PFOs while only 3 of 22 patients studied had a PFO (Grade III or more) considered large enough to cause right to left shunting. Nevertheless, this hypothesis was favoured by Soliman et al who concluded that approximately half of individuals with severe COPD and a PFO demonstrate systemic arterial oxygen desaturation after the Valsalva maneuver, albeit in the absence of hypoxemia at rest. During exercise in patients with COPD there is significant recruitment of the abdominal muscles which may develop low frequency fatigue, ${ }^{22,23}$ and since this is also the intention during a Valsalva maneuver we hypothesized, based on the data of Soliman et al, that there would be increased shunting. As is evident in Figure 1 this was indeed the case although the increase is not linear. Specifically, in COPD patients with a PFO the esophageal pressure swing seemed, as we have previously described, to increase linearly whereas the number of HITS did not. Interestingly, although the PFO group started with a lower $\mathrm{PaO}_{2}$ than those patients without a PFO, this gap narrowed by end exercise. The reason for this is not obvious since at the anaerobic threshold the PFO patients exhibited less rather than more minute ventilation per unit of carbon dioxide excreted ( $V^{\prime} \mathrm{E} / \mathrm{V}^{\prime} \mathrm{CO}_{2}$ ), although the latter could reflect exercise-induced pulmonary hypertension.

An alternative reason for patients with a PFO to be more hypoxic is that they have worse lung disease although the effect of $\mathrm{PFO}$ s on $\mathrm{PaO}_{2}$ was independent of TLco and other lung function parameters in multivariate analysis. It could be the case that more severe lung function impairment, in particular a greater degree of emphysema, as evidenced by the reduced TLco, predisposes to the development of PFOs, or of PFOs which are detectable in vivo. Prospective studies are needed to answer this or to establish whether this was simply a chance finding. The observation that patients with a PFO are more hypoxic is also interesting given recent findings in a large cohort of COPD patients that conventional pulmonary function measures only explain $26 \%$ of the variance in $\mathrm{PaO}_{2}{ }^{24}$

Our studies certainly point to an absence of functional impact of PFOs, at least in early COPD. Considering the group as a whole, the 6MWT did not differ between those who had a PFO and those who did not. Moreover, in the subset which progressed to cardiopulmonary exercise study, neither the peak oxygen uptake, whether expressed as $\mathrm{ml} / \mathrm{min} / \mathrm{kg}$ or percent predicted, nor peak workload differed between those who did and did not have a PFO. This lack of impact is more striking if one considers that the PFO group had worse lung function. Following our prior study ${ }^{3}$ we had been concerned about ensuring that the lack of impaired exercise tolerance associated with PFO was not due to a masking effect conferred by impaired pulmonary mechanics. In the prior study, mean peak $\mathrm{V}_{\mathrm{E}}$ was approximately $32 \mathrm{l} / \mathrm{min}$ which is appropriate for patients with GOLD stage III/ IV disease. In this study the PFO patients reached a mean $\mathrm{V}_{\mathrm{E}}$ of $65 \mathrm{l} / \mathrm{min}$ and the $\mathrm{PFO}^{+}$patients achieved 54 $1 /$ min (the difference not being statistically significant). In both cases we attribute the much improved exercise performance to the lesser impairment of $\mathrm{FEV}_{1}$, again arguing against a role for PFOs.

\section{Limitations}

Our study had several limitations although these are mitigated to some extent by our prior observations in patients with GOLD III/IV stage disease. ${ }^{3}$ First, the small sample size and absence of a control group makes it very difficult to clearly address the hypothesis that $\mathrm{PFO}$ prevalence is increased in mild COPD. Furthermore, only a few large PFOs (which are more likely to be associated with larger right to left shunt amount) were detected thus reducing the chance of identifying a $\mathrm{PFO}$ influence on hypoxemia and exercise tolerance. Secondly, the TCD is a simple and reliable technique to detect right to left shunting but it is not as accurate in distinguishing the nature of an intracardiac shunt (atrial septal defect, PFO, or other) as the TEE, although these techniques are unsuitable for exercise. Moreover, an echocardiogram could have been useful to determine the presence of pulmonary arterial hypertension and in this degree, providing greater depth to our findings. Thirdly, the lack of lung imaging studies do not allow us to ascertain the degree of emphysema or of smokingrelated interstitial lung disease in our COPD patients making it difficult to attribute the greater hypoxemia in the $\mathrm{PFO}^{+}$group just to the $\mathrm{PFO}$ influence. Finally, due to the complexity of the exercise tests, some data were not good enough to be considered for analysis and when 
this is taken into account the small-sized cohort may have lacked statistical power.

\section{Conclusions}

Our study shows that COPD patients with a PFO suffer a greater hypoxemia and do develop increased right to left shunting during exercise but, their exercise performance is not impaired. Moreover, despite the small study size, our data seem to confirm PFOs are not uncommon in COPD patients, which is consistent with previous works. However, our data do not support finding or closing PFOs in GOLD stage II COPD, at least for the reason of improving exercise performance.

\section{Acknowledgements}

Dario Martolini contributed to generation of the idea, contributed substantially to data acquisition and produced the first draft of the manuscript, Rebecca Tanner and Claire Davey contributed to patient recruitment and data acquisition, Mehul Patel contributed to the first draft of the manuscript and helped with statistical analysis, Davide Elia contributed to technique and reliable data acquisition, Helen Purcell provided a substantial help to perform all the CPET. Paolo Palange, Nicholas S. Hopkinson and Michael I. Polkey conceived the idea and critically reviewed the data and the manuscript. In addition, Hopkinson and Polkey supervised collection of the data on a day-to- day basis.

\section{Declaration of Interest}

The authors declare no conflict of interest with the exception of Michael Polkey whose institution has received awards from the British Heart Foundation and from NMT medical for research (other than the present study) into PFO. The present study was supported by the NIHR Respiratory Biomedical Research Unit at the Royal Brompton and Harefield NHS Foundation Trust and Imperial College who partially fund Dr. Polkey's salary and wholly funded Claire Davey. 


\section{References}

1. Calvert PA, Rana BS, Kydd AC, Shapiro LM. Patent foramen ovale: anatomy, outcomes, and closure. Nat Rev Cardiol. 2011; 8(3):148-160. doi: 10.1038/nrcardio.2010.224.

2. Hagen PT, Scholz DG, Edwards WD. Incidence and size of patent foramen ovale during the first 10 decades of life: an autopsy study of 965 normal hearts. Mayo Clin Proc. 1984; 59(1):1720. doi: 10.1016/S0025-6196(12)60336-X.

3. Shaikh ZF, Kelly JL, Shrikrishna D, et al. Patent foramen ovale is not associated with hypoxemia in severe chronic obstructive pulmonary disease and does not impair exercise performance. Am J Respir Crit Med. 2014;189(5):540-547. doi: 10.1164/ rccm.201309-16180C.

4. Soliman A, Shanoudy H, Liu J, Russell DC, Jarmukli NF. Increased prevalence of patent foramen ovale in patients with severe chronic obstructive pulmonary disease. J Am Soc Echocardiogr. 1999; 12(2):99-105. doi: 10.1016/S08947317(99)70121-5.

5. Hacievliyagil SS, Gunen H, Kosar FM, Sahin I, Kilic T. Prevalence and clinical significance of a patent foramen ovale in patients with chronic obstructive pulmonary disease. Respir Med. 2006;100(5):903-910. doi: 10.1016/j. rmed.2005.08.015.

6. Kilic H, Balci MM, Aksoy MN, et al. Patent foramen ovale among patients with mild chronic obstructive pulmonary disease and unexplained hypoxia. Echocardiography. 2010; 27(6):687690. doi: $10.1111 /$ j.1540-8175.2009.01105.x.

7. Kelly JL, Elkin SL, Fluxman J, Polkey MI, Soljak MA, Hopkinson NS. Breathlessness and skeletal muscle weakness in patients undergoing lung health screening in primary care. COPD. 2013; 10(1):40-54. doi: 10.3109/15412555.2012.727923.

8. Raghavan N, Guenette JA, O'Donnell DE. The role of pharmacotherapy in mild to moderate chronic obstructive pulmonary disease. Ther Adv Respir Dis. 2011;5(4):245-254. doi: $10.1177 / 1753465811398373$.

9. Vestbo J, Hurd SS, Agusti AG, et al. Global strategy for the diagnosis, management and prevention of chronic obstructive pulmonary disease, GOLD executive summary. Am $J$ Respir Crit Care Med. 2013;187(4):347-365. doi: 10.1164/ rccm.201204-0596PP.

10. Caputi L, Carriero MR, Falcone C, et al. Transcranial Doppler and transesophageal echocardiography: comparison of both techniques and prospective clinical relevance of transcranial Doppler in patent foramen ovale detection. $J$ Stroke Cerebrovasc Dis. 2009;18 (5):343-348. doi: 10.1016/j. jstrokecerebrovasdis.2008.12.001.

11. Spencer MP, Moehring MA, Jesurum J, Gray WA, Olsen JV, Reisman M. Power m-mode transcranial Doppler for diagnosis of patent foramen ovale and assessing transcatheter closure. $J$ Neuroimaging. 2004 Oct;14(4):342-349. doi: 10.1111/ j.1552-6569.2004.tb00261.x
12. Jauss M, Zanette E. Detection of right-to-left shunt with ultrasound contrast agent and transcranial Doppler sonography. Cerebrovasc Dis. 2000;10(6):490-496. doi: 10.1159/000016119.

13. Zavorsky GS, Cao J, Mayo NE, Gabbay R, Murias JM. Arterial versus capillary blood gases: a meta-analysis. Respir Physiol Neurobiol. 2007; 155(3):268-279. doi: 10.1016/j.resp.2006.07.002.

14. Macintyre N, Crapo RO, Viegi G, et al. Standardisation of the single-breath determination of carbon monoxide uptake in the lung. Eur Respir J. 2005; 26(4):720-735. doi: 10.1183/09031936.05.00034905.

15. Miller MR, Hankinson J, Brusasco V, et al. Standardisation of spirometry. Eur Respir J. 2005; 26(2):319-338. doi: 10.1183/09031936.05.00034805.

16. Wanger J, Clausen JL, Coates A, et al. Standardisation of the measurement of lung volumes. Eur Respir J. 2005; 26(3):511522. doi: 10.1183/09031936.05.00035005.

17. Brooks D, Solway S, Gibbons WJ. ATS statement on six-minute walk test. Am J Respir Crit Care Med. [CommentLetter]. 2003; 167(9):1287. doi: 10.1164/ajrccm.167.9.950.

18. Shaikh ZF, Jaye J, Ward N, et al. Patent foramen ovale in severe obstructive sleep apnea: clinical features and effects of closure. Chest. 2013; 143(1):56-63. doi: 10.1378/chest.12-0334.

19. Boerrigter BG, Boonstra A, Westerhof N, Postmus PE, Vonk-Noordegraaf A. Cardiac shunt in COPD as a cause of severe hypoxaemia: probably not so uncommon after all. Eur Respir J. 2011;37(4):960-962. doi: 10.1183/09031936.00058410.

20. Gonzalez-Alujas T, Evangelista A, Santamarina E, et al. Diagnosis and quantification of patent foramen ovale. Which is the reference technique? Simultaneous study with transcranial Doppler, transthoracic and transesophageal echocardiography. Rev Esp Cardiol. 2011;64(2):133-139.

21. Zito C, Dattilo G, Oreto G, et al. Patent foramen ovale: comparison among diagnostic strategies in cryptogenic stroke and migraine. Echocardiography. 2009; 26(5):495-503. doi: 10.1111/j.1540-8175.2008.00852.x.

22. Kyroussis D, Polkey MI, Hamnegard CH, Mills GH, Green M, Moxham J. Respiratory muscle activity in patients with COPD walking to exhaustion with and without pressure support. Eur Respir J. 2000; 15(4):649-655. doi: 10.1034/j.13993003.2000.15d05.x

23. Hopkinson NS, Dayer MJ, Moxham J, Polkey MI. Abdominal muscle fatigue following exercise in chronic obstructive pulmonary disease. Respir Res. 2010; 11:15. doi: 10.1186/1465-9921-11-15.

24. Boutou AK, Shrikrishna D, Tanner RJ, et al. Lung function indices for predicting mortality in COPD. Eur Respir J. 2013; 42(3):616-625. doi: 10.1183/09031936.00146012. 